\title{
Scenario analysis for promoting clean cooking in Sub-Saharan Africa: Costs and benefits
}

\author{
Anteneh G. Dagnachew ${ }^{\text {a, b, * }}$, Andries F. Hof ${ }^{\text {a, b }}$, Paul L. Lucas ${ }^{\text {a }}$, Detlef P. van Vuuren ${ }^{\text {a, b }}$ \\ a PBL Netherlands Environmental Assessment Agency, The Hague, the Netherlands \\ ${ }^{\mathrm{b}}$ Copernicus Institute of Sustainable Development, Utrecht University, Utrecht, the Netherlands
}

\section{A R T I C L E I N F O}

\section{Article history:}

Received 19 June 2019

Received in revised form

25 November 2019

Accepted 26 November 2019

Available online 29 November 2019

\section{Keywords:}

Sub-Saharan Africa

Clean cooking

Biomass

Sustainable development goals

Universal energy access

Climate change

\begin{abstract}
A B S T R A C T
Nearly 900 million people in Sub-Saharan Africa rely on traditional biomass for cooking, with negative impacts on health, biodiversity and the climate. In this study, we use the IMAGE modellingframework to construct two sets of scenarios for promoting clean cooking solutions. In the first set, specific policy options to promote clean cooking are evaluated, while in the second the SDG target to achieve universal access to modern cooking energy by 2030 is imposed. The study adds knowledge to understanding the impact of individual policy options on access to clean cooking solutions, and provides insight into synergies and trade-offs of achieving the SDG targets on human health, biodiversity and climate change. The results show that, in the absence of coordinated actions, enabling policies and scaled-up finance, the number of people in Sub-Saharan Africa relying on traditional biomass cookstoves could amount to 660 -820 million by 2030 . Subsidies on specific clean cooking technologies or fuels could increase their use substantially, but could hinder the uptake of alternative clean cooking fuels or technologies. Meeting the SDG target has considerable social, environmental and economic benefits, and could even lead to lower total fuel expenditures. However, investments in cookstoves need to be quadrupled relative to baseline. ๑) 2019 Elsevier Ltd. All rights reserved.
\end{abstract}

\section{Introduction}

Nearly 900 million people in Sub-Saharan Africa (SSA) rely on traditional biomass (wood, charcoal, dung, or agricultural residues) for cooking [1]. This has major health consequences, as inefficient and incomplete combustion of traditional biomass is associated with high levels of hazardous air pollutants, including carbon monoxide and fine particulate matter [2]. The evidence links household air pollution (HAP) from cooking with solid fuels to over 390 thousand premature deaths in SSA in 2017, 35\% of the deaths occurring amongst children under 5 years of age [3].

The use of fuelwood and charcoal also exerts a large pressure on local and regional environments, including deforestation, forest degradation and destruction [4,5], and soil degradation and erosion [6]. In addition, residential biomass burning contributes to climate change through black carbon emissions [7] and, when the biomass used is harvested unsustainably, through net $\mathrm{CO}_{2}$ emissions [8]. Shifting to clean cooking fuels and technologies therefore has both

\footnotetext{
* Corresponding author., PBL, PO Box 30314, 2500 GH, The Hague, the Netherlands

E-mail address: Anteneh.dagnachew@pbl.nl (A.G. Dagnachew).
}

social and environmental benefits, which is internationally recognized through Sustainable Development Goal (SDG) target 7.1 (achieving universal access to affordable, reliable, and modern energy services).

Long-term targets require decision-making that considers plausible future outcomes and their potential implications. Modelbased scenarios can be used for this, informing policymakers how a transition to clean cooking solutions could take place. Some studies have already explored scenarios for clean cooking access in various regions. Pachauri, van Ruijven [9] assess investments requirements and impacts of achieving universal access to clean-combusting cooking fuels and stoves by 2030 using two alternative modelling frameworks. Cameron, Pachauri [10] quantified the costs of supporting policies to make universal access to clean cooking affordable in South Asia. Fuso Nerini, Ray [11] compare various cooking solutions on the basis of 'levelized cost of cooking a meal' in Nyeri County, Kenya. Pachauri, Rao [12] use a model to simulate future pathways of clean cooking uptake and the outlook for achieving SDG 7.1 in Guatemala, Honduras and Nicaragua. Although these studies looked at access to clean cooking in various scales and contexts, the possible development routes for clean cooking in SSA, one of the regions where the use of traditional fuels is prevalent, 
have not been sufficiently explored. This study addresses that gap by exploring several policy options and pathways towards universal access to clean cooking solutions in SSA, and analyses the consequences of these options and pathways for cookstove and fuel costs, health, wood demand, and emissions. In addition to providing long- and short-term policy insights, the study contributes to existing academic literature by assessing the synergies and tradeoffs between various SDGs in the context of universal energy access in SSA.

In this paper, we present two sets of scenarios for promoting cooking solutions in SSA. In the first set, specific policy measures are introduced to analyse the effectiveness and consequences of these policies. In a second set, the scenarios are set up in such a way that access to clean cooking solutions for all households in SSA is achieved by 2030 using a back-casting method. This set of scenarios provides insight into the requirements and consequences of achieving certain predefined targets for clean cooking. The scenarios are developed using the IMAGE integrated assessment model framework [13]. More specifically, extended versions of the residential sector end-use models REMI [14] and REMG [15] within the IMAGE framework are used. The scenarios consider historic developments and the availability of fuels and infrastructure, and show required expenditures in both capital (i.e. cookstoves) and fuels, impacts on child health, wood demand, and greenhouse gas emissions. The main objective of this scenario analysis is to provide insight in to the role of different cooking technologies, the investment needs and the fuel cost in achieving universal access to clean cooking in SSA, as well as to assess the consequences of different scenarios for biodiversity, health, and the climate.

The paper is organised as follows. Section 2 provides the methodology, including the main assumptions on costs of and emissions from fuels \& technologies included in the study and the scenario descriptions, followed by section 3 that presents the results. Section 4 contains the discussion and section 5 concludes with policy recommendations.

\section{Methodology}

Our study relies on the integrated assessment model IMAGE [13] and its sub-models to provide an integrated and systemic view on modern cooking solutions. This section discusses the current situation, the different modules used in our analysis, the most relevant technology costs and socioeconomic assumptions, and presents a description of the scenarios.

\subsection{Current use of cooking fuel in SSA}

In Sub-Saharan Africa nearly 900 million people relied on solid biomass as their primary cooking energy source in 2016 (Fig. 1). Nearly a quarter of that was charcoal, the rest being firewood (73\%), dung (2\%) or crop residue (1\%), mainly used in inefficient stoves or traditional three-stone fires. This is a decline of a meagre 3\%-points since 2000 [16]. The use of traditional biomass is particularly dominant in poor rural settlements because of either its low cost, sometimes collected for free [17], the lack of available alternatives [18], or cultural factors (e.g. preferences and taste) [19]. After biomass, kerosene is the second most prevalent fuel used for cooking in SSA, particularly in urban areas. In 2016, $12 \%$ of the urban and $4 \%$ of rural households in SSA used kerosene as the main cooking fuel. In the same year, LPG was the primary cooking fuel for $10 \%$ of SSA urban households. LPG and natural gas are barely used in rural areas, mainly due to lack of distribution systems [20] and the relatively high and fluctuating price of the fuel in combination with very low-income levels [21]. Finally, electricity, the cleanest cooking solution with respect to HAP, is primarily used in Southern
Africa.

There are similarities and considerable differences between the sub-regions (Fig. 1). The share of traditional biomass cookstove use is similar between western \& central Africa and eastern Africa, and slightly lower in the rest of southern Africa. Kerosene has a relatively large share in western \& central Africa and the Republic of South Africa, improved cookstoves are more prevalent in eastern Africa, and electricity is used often in southern Africa. The share of LPG is the largest in the rest of southern Africa.

\subsection{Model description}

For the scenarios analyses the IMAGE 3.0 integrated assessment modelling framework [13] is used, which includes the TIMER energy-system simulation model [24], IMAGE-LandManagement [25] and the GISMO health model [26,27]. The IMAGE framework is a suite of simulation models that together represent interactions between society, the biosphere and the climate system to assess sustainability issues such as climate change, biodiversity loss and human well-being. The model includes a detailed description of the energy and land-use system and simulates socio-economic and environmental parameters on a geographical grid of 30 by $30 \mathrm{~min}$ or 5 by $5 \mathrm{~min}$ (around $50 \mathrm{~km}$ and $10 \mathrm{~km}$ at the equator, respectively), depending on the specific variable. The IMAGE 3.0 modelling framework has been used in similar studies in the past and the results are published in peer reviewed articles [15,25,28-31].

The TIMER model describes demand and supply of key energy carriers for 26 world regions [24]. Important issues that can be addressed with the model include transitions to modern and sustainable energy supplies, energy access, future demand projections, the role of the energy conversion sector and various energy technologies in achieving a more sustainable energy system, and computing emissions of greenhouse gases related to energy conversion.

The mix of cooking fuels and technologies is determined with REMG, which is part of the TIMER model [15]. REMG is a stylized bottom-up simulation module, which describes energy demand for cooking (and other residential end-use functions such as water heating, space heating, space cooling and appliance use) [15] (Fig. 2). The model describes household energy demand and the fuel mix for five income classes, for both rural and urban households. Cooking energy demand is primarily driven by population size and household income (Fig. 2). The cooking fuel and technology options include: mineral coal, traditional biomass (in combination with traditional and improved cookstoves), modern biomass (in combination with advanced cookstoves), kerosene, LPG, biogas, natural gas and electricity. The model uses a capital vintage model for the stock of stoves. Shares of different stoves in the cooking energy mix are the result from additional purchases and depreciation after the technical lifetime. The cooking technology mix serves as input to the other modules to determine the capital cost, the fuel expenditure, the health impact and the environmental impact.

The capital costs and annual fuel expenditure are determined based on the market shares of the different cooking technologies and their efficiencies. Market shares of purchases are determined using perceived costs of different cooking technologies with a multinomial logit allocation. It thereby assigns the largest market share to the cheapest energy technologies, while technologies that have higher costs get lower shares, considering heterogeneous local characteristics where relevant. The perceived costs include monetary and non-monetary costs. The monetary costs are the sum of the capital costs and the operating (fuel and maintenance) costs. The annualized capital costs are determined by the cost of the cooking technology and accessories and consumer discount rates. 


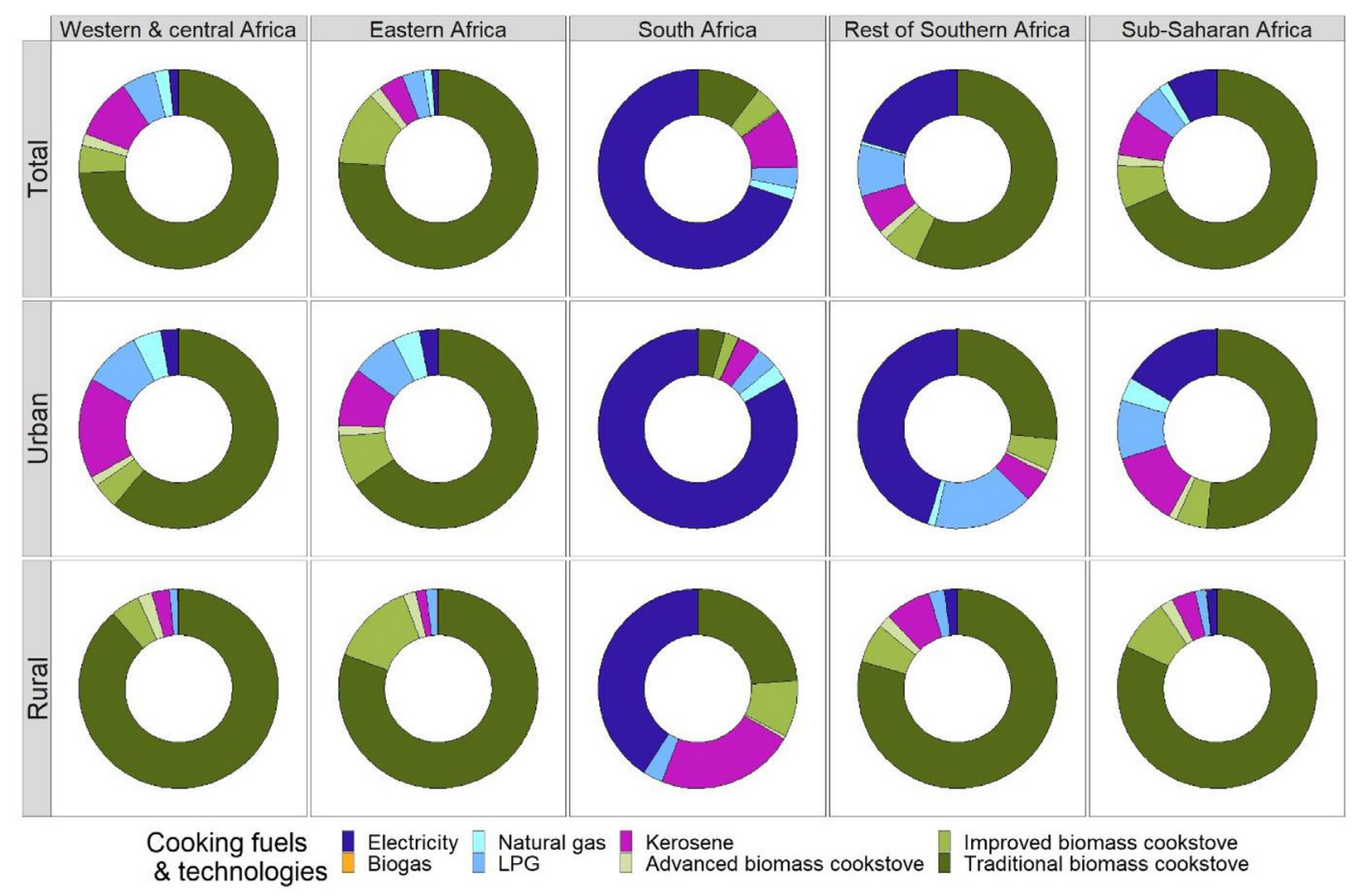

Fig. 1. Regional cooking energy mix in 2016 in SSA [22,23].

The discount rates are higher for low-income households and decrease with income. The non-monetary costs represent the fact that fuel choice is not only the product of economic factors alone; especially in poorer households where cultural aspects, lack of awareness on advantages of cleaner fuels, and the opportunity cost of traditional biomass play important roles. It is assumed that the non-monetary costs for traditional fuels (i.e. biomass, kerosene) increase with income. More details on REMG are presented in section 1 of the supplementary information (SI).

GISMO is used to determine the health impacts of the cooking energy mix in the different scenarios. The health model describes the causal chain between health-risk factors, morbidity and mortality, based on a multi-state approach, distinguishing risk exposure, disease incidence and death [26,27]. The GISMO model is used to assess future developments in child mortality attributable to HAP, focussing on acute lower respiratory infections (ALRI). The model is updated to total ALRI incidence and mortality data and technology specific of the Global Burden of Disease study 2017 [3]. Exposure specific Relative Risk (RR) ${ }^{1}$ are used to relate the use of specific cooking technologies to increased risk of ALRI incidence and death [3] (see Table 1). Important inputs for these calculations are the household cooking energy mix from REMG, age-specific population projections and per capita GDP projections.

IMAGE-LandManagement model [25] is used to determine potential biomass supply. The demand for fuelwood relative to the potential supply from natural regrowth is an indicator for the risk of additional deforestation. The total wood supply (ton dry matter/ year) is determined based on the potential growth of stems and branches in natural vegetation, excluding projected natural area, cropland, grazing land or built-up areas. Demand for wood is calculated based on the cooking energy mix for the different

\footnotetext{
${ }^{1}$ RR ratios indicate the increased risk of illness or mortality while exposed to a certain risk factor, as compared to a situation with no increased risks (i.e. no household air pollution, $R R=1$ ).
}

scenarios, a wood-to-charcoal conversion efficiency of $20 \%$, a woodto-firewood conversion efficiency of $100 \%$, and the energy content of energy carriers as given in Table 2 .

\subsection{Technology and cost assumptions}

Here we summarize most important assumptions on technology performances and cost. These assumptions are based on previous studies. A detailed description of the assumptions and their respective sources can be found in section 2 of the SI. The most important assumptions in the REMG model are the useful energy demand for cooking, and current and future costs of fuels and cookstoves, which together with household per capita income levels, determine the choice for cooking technologies in the model.

The amount of useful energy needed for cooking is an important assumption for determining the technology choice, which in turn, determines associated capital investments and fuel expenditures. The amount of energy that a household requires for cooking has been the subject of numerous studies. However, large difference are found in the estimates, ranging from $0.36 \mathrm{MJ} /$ capita/meal [32] to 6 $\mathrm{MJ} /$ capita/meal [33]. Daioglou, van Ruijven [15] found no statistically significant relationship between energy for cooking and income or geographical region. Hence, a constant value of $3 \mathrm{MJ} /$ capita/day (the literature mean) of useful energy for all households and regions is used. To address this uncertainty, we have presented the impact of useful energy demand on the cooking energy mix in SSA in section 5 of the SI (from which it can be concluded that the shares of cooking technologies and fuels are not sensitive to the level of useful energy needed).

Table 1 presents assumed current and future average capital cost (stove and accessory costs) and the annual average operating cost (fuel and maintenance costs) of the cooking fuel and technology combinations included in the model. These costs can differ per region and settlement. The values provided in the table are averages across the whole of Sub-Saharan Africa.

Other important assumptions include the conversion 


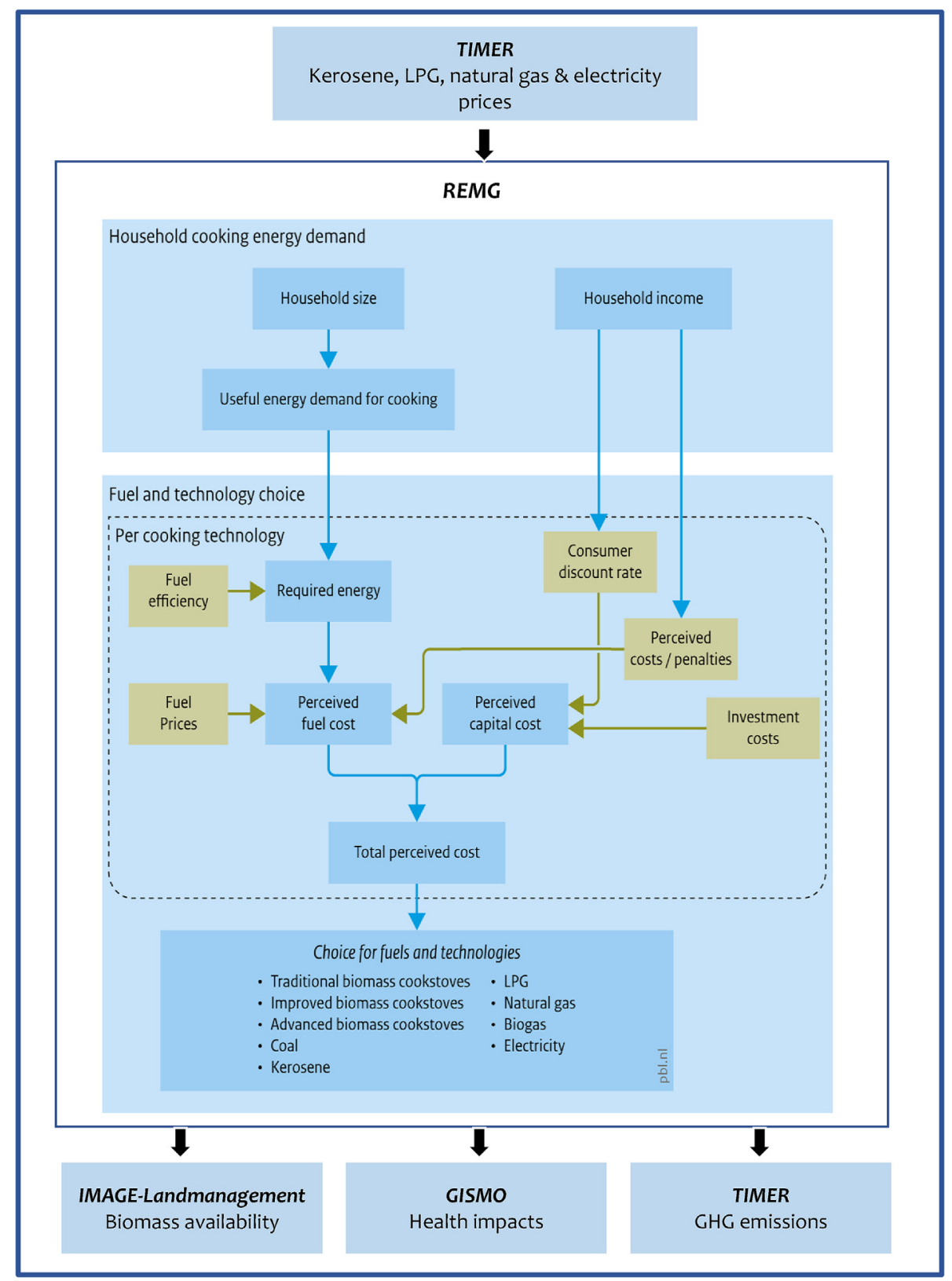

Fig. 2. Cooking fuel and technology choice drivers in REMG and interaction with other sub-models (adapted from Daioglou et al., 2012).

Table 1

Assumptions on Conversion efficiencies [34,35], health effects [35], and average costs [36-38].

\begin{tabular}{|c|c|c|c|c|c|c|c|c|c|}
\hline \multirow[t]{2}{*}{ Fuel } & \multirow[t]{2}{*}{ Cookstove technology } & \multicolumn{2}{|c|}{$\begin{array}{l}\text { Conversion } \\
\text { efficiency (\%) }\end{array}$} & \multicolumn{2}{|c|}{$\begin{array}{l}\text { 24-h PM2.5 } \\
\text { concentrations }(\mu \mathrm{g} / \\
\left.\mathrm{m}^{3}\right)\end{array}$} & \multicolumn{2}{|c|}{ Capital cost (USD) } & \multicolumn{2}{|c|}{$\begin{array}{l}\text { Average annual } \\
\text { operating cost } \\
(\text { USD) }\end{array}$} \\
\hline & & 2015 & 2030 & 2015 & 2030 & 2015 & 2030 & 2015 & 2030 \\
\hline \multirow[t]{2}{*}{ Traditional biomass } & Traditional cookstove & 12 & $14^{\mathrm{b}}$ & 500 & 500 & 0.5 & 0.5 & 91 & 69 \\
\hline & Improved cookstove & 30 & 33 & 200 & 150 & 25 & 20 & 35 & 28 \\
\hline Modern biomass & Advanced cookstove & 40 & 47 & 75 & 60 & 65 & 51 & 108 & 84 \\
\hline Mineral Coal & Improved coal cookstove & 25 & 25 & 200 & 150 & 25 & 25 & 62 & 72 \\
\hline Kerosene & Kerosene stove & 35 & 44 & 50 & 40 & 20 & 20 & 271 & 223 \\
\hline LPG & Single burner & 50 & 58 & 20 & 10 & 55 & 39 & 159 & 139 \\
\hline Natural gas & Gas stove & 50 & 57 & 0 & 0 & 55 & 39 & 103 & 82 \\
\hline Biogas & Gas stove \& digester & 40 & 50 & 0 & 0 & 550 & 430 & 9 & 8 \\
\hline Electricity & Electric/induction & 75 & 86 & 0 & 0 & 70 & 55 & 246 & 198 \\
\hline
\end{tabular}

a Data includes interpolations.

b The scenarios have been discussed at the clean cooking forum 2017 in Delhi, at SNV during a cooking experts meeting, and a Dutch SPARK meeting in The Hague. 
Table 2

Energy content and emission factors of cooking fuels [40,41].

\begin{tabular}{lll}
\hline Fuel & Energy content & $\mathrm{CO}_{2} \mathrm{e}$ emission factor \\
\hline Mineral Coal & $46 \mathrm{MJ} / \mathrm{kg}$ & $238 \mathrm{~kg} / \mathrm{GJ}$ \\
Firewood, air dried (15\% moisture) & $16 \mathrm{MJ} / \mathrm{kg}$ & $217 \mathrm{~kg} / \mathrm{GJ}$ \\
Charcoal & $30 \mathrm{MJ} / \mathrm{kg}$ & $218 \mathrm{~kg} / \mathrm{GJ}$ \\
Kerosene & $43 \mathrm{MJ} / \mathrm{kg}$ & $126 \mathrm{~kg} / \mathrm{GJ}$ \\
Liquefied Petroleum Gas (LPG) & $45.5 \mathrm{MJ} / \mathrm{kg}$ & $67 \mathrm{~kg} / \mathrm{GJ}$ \\
Natural gas & $38 \mathrm{MJ} / \mathrm{m}^{3}$ & $56 \mathrm{~kg} / \mathrm{GJ}$ \\
Bio-gas & $22.8 \mathrm{MJ} / \mathrm{m}^{3}$ & $4 \mathrm{~kg} / \mathrm{GJ}$ \\
Electricity & $3.6 \mathrm{MJ} / \mathrm{kWh}$ & $70-250 \mathrm{~kg} / \mathrm{GWh}^{2}$ \\
\hline
\end{tabular}

efficiencies of the fuels and technology related to $\mathrm{PM}_{2.5}$ concentrations (see Table 1). The conversion efficiencies determine secondary energy demand (e.g. amount of wood for traditional biomass), and thereby the operating cost as well as potential environmental consequences. Technology related $24-\mathrm{h} \mathrm{PM}_{2.5}$ concentration determine exposure to HAP and are used to calculate related child mortality due to ALRI. For the conversion efficiencies, average field values are used for 2015, which improve linearly to maximum laboratory levels in 2050 as given in table 6 of [34] and Fig. 11.2 of [35]. For average $\mathrm{PM}_{2.5}$ concentrations, the average values reported in Fig. 11 of [35] is used in 2015, linearly declining to the lowest value in 2050 .

Finally, the GHG emissions from mineral coal, biomass, kerosene, LPG, and natural gas are calculated based on the emission factor given in Table 2 and the total energy input required to produce the desired amount of useful energy. For electricity, the GHG emissions are calculated based on the required secondary energy input and the regional baseline projections of emissions from electricity production (that includes efficiency and transmission losses). For biomass cookstoves, it is assumed that the net $\mathrm{CO}_{2}$ emissions at the point of combustion of fuelwood is zero if it is sustainably harvested. Based on the estimates from Ref. [39], we assume that a third of the fuelwood is harvested unsustainable and hence adds $\mathrm{CO}_{2}$ emissions to the atmosphere. In this study, we consider the most important GHG emissions that include $\mathrm{CO}_{2}, \mathrm{CH}_{4}$, $\mathrm{N}_{2} \mathrm{O}$, black carbon $(\mathrm{BC})$ and organic carbon $(\mathrm{OC})$.

\subsection{Scenario descriptions}

The scenarios have been designed based on iterative discussions with relevant stakeholders that include governments, practitioners, aid organizations and the private sector. ${ }^{2}$ Two sets of scenarios are assessed: policy scenarios and target scenarios (Table 3).

The policy scenarios have been designed to assess the effect of specific policy interventions that stimulate the adoption of cleaner cooking fuels/technologies. Specifically, the following policies are assessed: a biomass cookstove capital subsidy, a biogas digester capital subsidy, and a modern fuel (LPG and natural gas) distributions system subsidy.

The target scenarios are designed to show different pathways to achieve the SDG target of universal access to clean and modern cooking energy in SSA. These scenarios arise from the need for radical measures to meet the SDG7 target of achieving universal access to clean and modern energy. We consider low-emission biomass cookstove, such as improved and advanced biomass cookstoves, transitional technologies that are beneficial to health and the environment. As such, we examined two overall pathways: a complete phase out of traditional biomass cookstoves by 2030 (No

\footnotetext{
2 Traditional biomass cookstove includes various self-made cookstoves ranging from three-stone fire to basic mud stoves, and we assume that the use of threestone fire declines in the future.
}

traditional cookstoves) and a complete phase-out of solid biomass (Modern fuel) by 2030. Additionally, for the latter pathway we have developed a scenario in which we assumed a change in cooking behaviour (a switch to pre-cooked food or low energy intensive diet) for all households that cook on electricity - leading to a 50\% reduction in final energy use (Electric cooking).

All scenarios are based on the SSP2 socio-economic pathway that assumes medium projections for population growth, urbanization and economic development. In 2030, SSA population is projected to grow to more than 1.3 billion [42], average GDP per capita to more than USD 3700 [43], and urbanization to nearly 50\% [44]. The sensitivity of socio-economic drivers on baseline developments is analysed in section 5 of the SI.

\section{Results}

This section provides the results for policy scenarios and target scenarios relative to the SSP2 baseline results. The scenarios are discussed in terms of future developments in the use of cooking fuels and technologies, related fuel and capital cost of stoves and accessories, and their implications on child mortality, the risk of forest degradation and deforestation, and GHG emissions. The results presented in this paper focus on 2030, the target year for the SDGs. However, for the policy scenarios, we found that the progress after 2030 is interesting as well. Projections to 2050 are therefore presented in section 4 of the SI.

\subsection{Cooking fuels and technologies}

The baseline projection shows a moderate switch away from traditional cookstoves by 2030.The share of the population relying on traditional biomass cookstoves declines from 70\% in 2016 to 55\% in 2030 (in absolute numbers increasing from 700 to 730 million people) under the baseline. This scenario leaves over a billion people without access to modern cooking solutions (i.e. biogas, LPG, natural gas and electricity).

The policy scenarios lead to lower shares of traditional biomass use but none of them lead to achieving the SDG target. In the Enhanced fuel distribution and Cookstove subsidy scenarios, about 150 million less people cook with traditional biomass cookstoves by 2030 relative to baseline (see Fig. 3), leaving 580 million people relying on traditional biomass cookstoves. The effect of a biogas digester subsidy on traditional cookstoves use is minimal by 2030 , the results show that the increase of biogas use is relatively small in the short term (as the investment requirement remains large even with the subsidy) and that it mainly replaces LPG and improved and advanced cookstoves.

Under the baseline scenario, $20 \%$ of the population cooks with modern fuels by 2030. The Enhanced fuel distribution scenario shows a higher share of modern fuels, with $30 \%$ of the population cooking on LPG or natural gas. As expected, the share of modern fuels in the Cookstove subsidy does not differ much from baseline, but the use of improved and advanced cookstoves is about twice as high as in the baseline. The shares of kerosene and electricity do not differ significantly between the baseline and policy scenarios.

After 2030, traditional biomass cookstoves use declines, mainly replaced by improved biomass cookstoves and LPG (see section 4 of the SI). This rapid decrease can be attributed to i) efficiency improvements of modern fuel-based technologies and improved and advanced cookstoves, ii) urbanization, and iii) the increase in household income. The impact of biogas subsidies also become considerable as household income increases and the price of digesters declines. The specific policies to promote clean cooking will accelerate the trend.

The target scenarios imply a strong deviation from the baseline, 
Table 3

Names and descriptions of the scenarios for Sub-Saharan Africa.

\begin{tabular}{|c|c|c|}
\hline Scenario set & Scenario name & Short description \\
\hline $\begin{array}{l}\text { Baseline } \\
\text { scenario }\end{array}$ & Baseline & Reference scenario without specific policies to stimulate clean cooking under SSP2 socio-economic projections. \\
\hline \multirow{3}{*}{$\begin{array}{l}\text { Policy } \\
\text { scenarios }\end{array}$} & Cookstove subsidy & A $50 \%$ subsidy on the retail prices of improved and advanced cookstoves, but no subsidy on fuel. \\
\hline & $\begin{array}{l}\text { Biogas digester } \\
\text { subsidy }\end{array}$ & A $50 \%$ subsidy on the retail price of biogas digesters. \\
\hline & $\begin{array}{l}\text { Enhanced fuel } \\
\text { distribution }\end{array}$ & $\begin{array}{l}\text { A fraction of LPG and (liquid) natural gas required for cooking is provided by infrastructure support or subsidy ( } 40 \% \text { in urban areas and } \\
100 \% \text { in rural areas), leading to lower gaseous fuel prices for the final consumer (by on average } 20-30 \% \text { for LPG and by } 30-50 \% \text { for } \\
\text { natural gas). }\end{array}$ \\
\hline \multirow[t]{3}{*}{$\begin{array}{l}\text { Target } \\
\text { scenarios }\end{array}$} & $\begin{array}{l}\text { No traditional } \\
\text { cookstoves }\end{array}$ & A complete phase out of solid biomass in combination with traditional cookstoves and kerosene cookstoves by 2030. \\
\hline & Modern fuel & A complete phase out of solid biomass, kerosene and mineral coal by 2030 . \\
\hline & Electric cooking & $\begin{array}{l}\text { A complete phase out of solid biomass, kerosene and mineral coal by } 2030 \text { and households cooking on electricity will use } 50 \% \text { less } \\
\text { energy due to changes in cooking behaviours. LPG, natural gas and biogas will remain as cooking options. }\end{array}$ \\
\hline
\end{tabular}

Note: extended description of the scenarios can be found in section 3 of the SI.

as more than half the population in SSA needs to transition to modern fuels. In the No traditional cookstoves scenario, more than half the population cook on biomass (either on improved or advanced cookstoves) and around a quarter use LPG in 2030, the rest covered with biogas, natural gas and electricity. In the Modern fuel scenario, an even more rapid transition is required. By 2030, liquid and gaseous fuels are used by $75 \%$ of the population. Biogas and electricity provide the rest of the population with clean cooking energy. If behavioural change for those households cooking on electricity is assumed (leading to a $50 \%$ lower energy demand as they switch to per-cooked food or less energy intensive diet), the results change considerably: the share of electricity in the cooking energy mix is projected to increase to more than $55 \%$ by 2030 , as shown under the electric cooking scenario. This is due to the low annual energy demand and hence low fuel expenditure for electricity. The energy saving gained from cooking behaviour change is in addition to the autonomous efficiency improvement shown in Table 1.

\subsection{Capital cost and fuel expenditure}

The annual fuel expenditure for cooking outweigh the annual capital cost by far, both in the baseline and in the policy and target scenarios (Fig. 4). In 2016, total annual fuel expenditure in SSA was about USD 23 billion, equalling USD 112 per household. Traditional biomass dominated the fuel expenditures with USD 14 billion (assuming average cost of USD 0.03 per kilogram for charcoal and firewood), followed by kerosene and electricity. In the baseline scenario, by 2030 , total annual fuel cost is projected to increase to around USD 30 billion, equalling USD 100 per household. Most of the policy scenarios show similar total fuel expenditures as baseline by 2030 , which is a direct consequence of small changes in fuel mix (see Fig. 3). The only major difference is found in the Enhanced fuel distribution scenario, which shows a much higher expenditure in gaseous fuels, displacing biomass, kerosene, and also electricity. However, in this scenario, governments or other stakeholders facilitating access to modern fuel bear $10 \%$ of the fuel cost. The

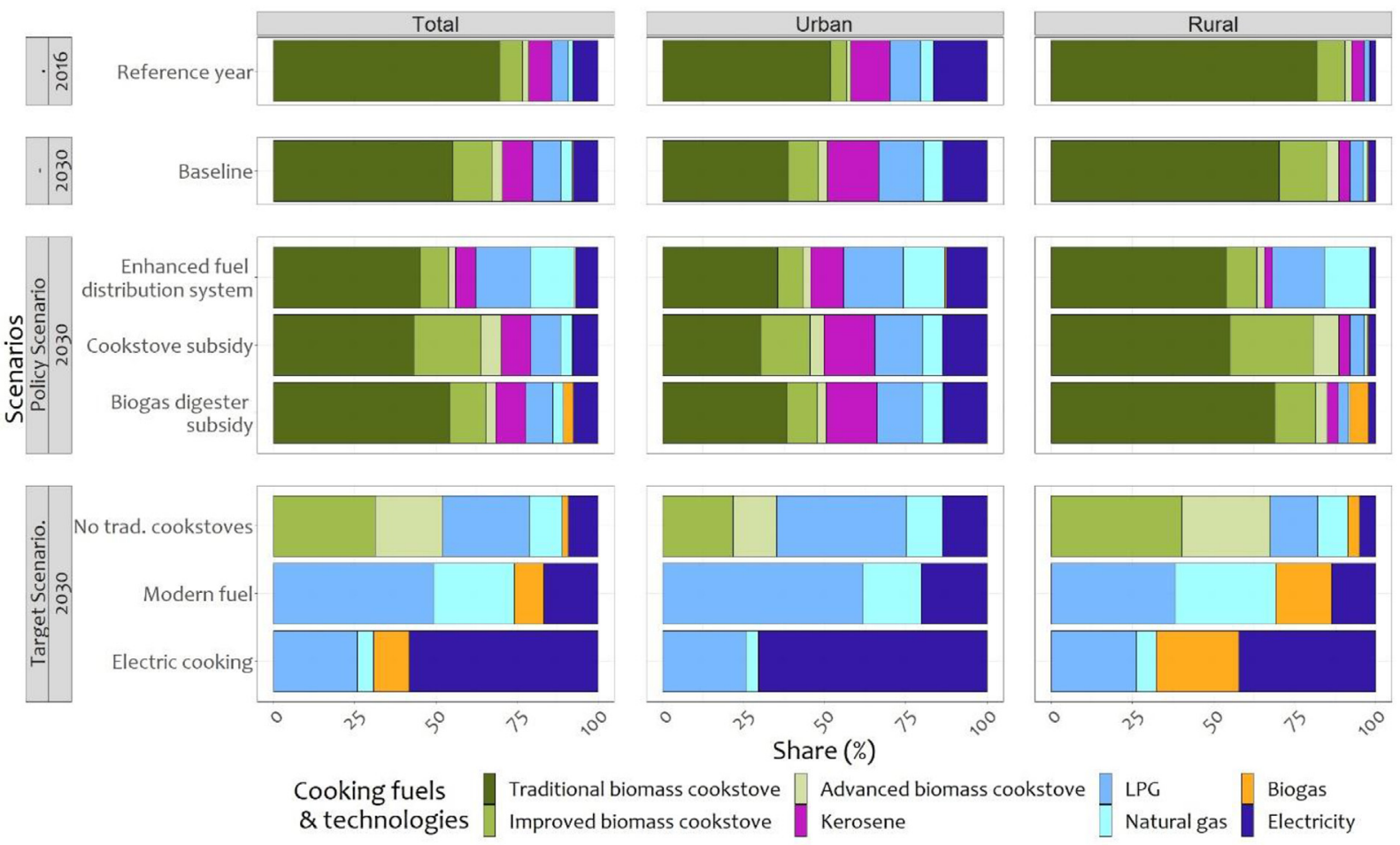

Fig. 3. Cooking energy mix in SSA. 


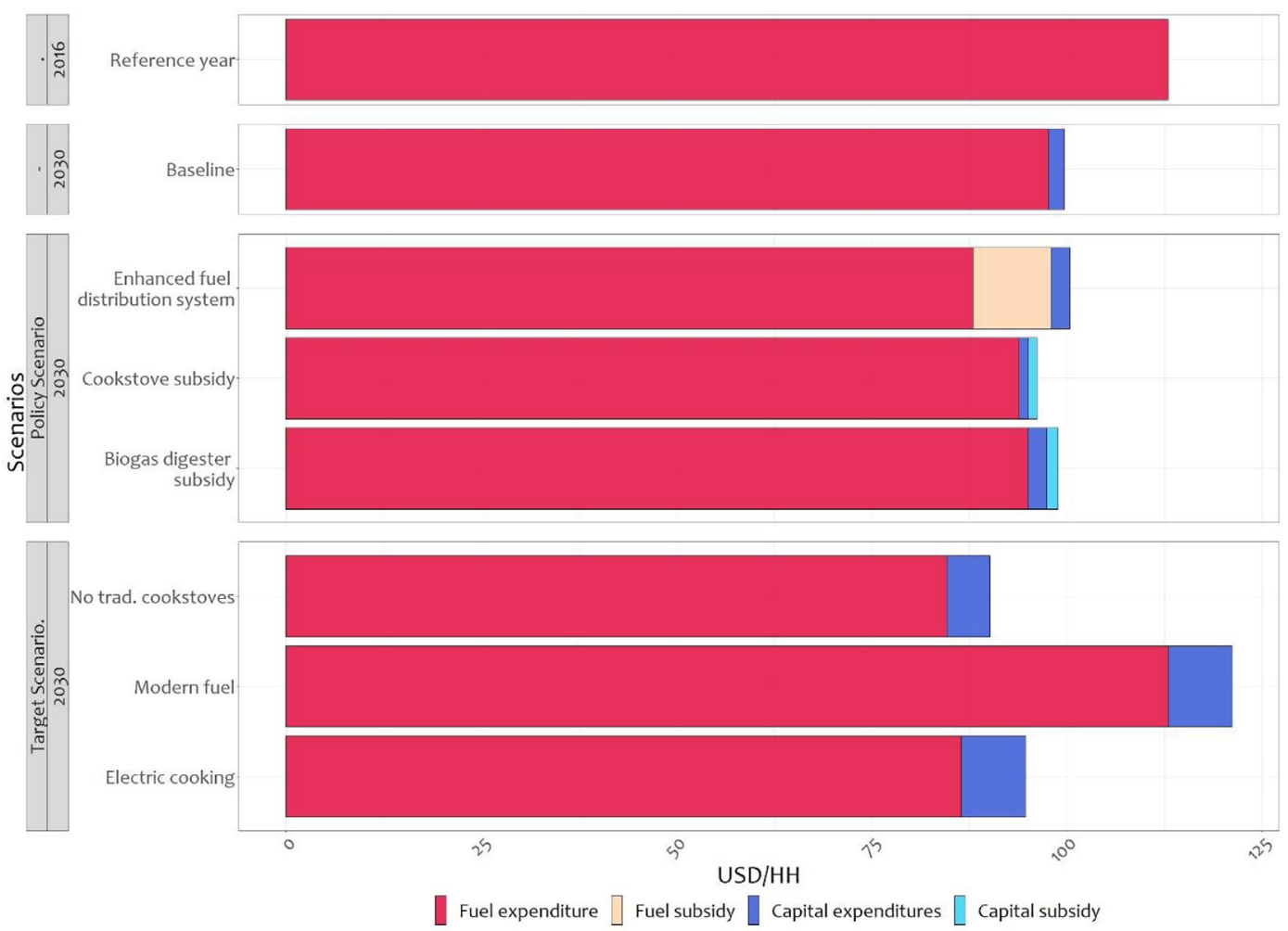

Fig. 4. Household annual cooking fuel and capital expenditure in SSA.

target scenarios show larger differences. Phasing out traditional cookstoves and kerosene leads to much lower average annual fuel cost, as more efficient biomass cookstoves are used and kerosene is expensive. However, if all biomass use is phased out (as in the modern fuel scenario), total fuel cost is projected to increase, as the cheap biomass used in improved cookstoves is being replaced by more expensive gaseous fuels and electricity. The electricity scenario shows lower annual fuel expenditure than most of the scenarios because of the lower energy use of the households cooking on electricity.

The total annual capital cost in the baseline scenario is 600 million USD in the period 2016-2030, equalling 2 USD per household. In the Cookstove subsidy scenario, the capital cost is projected to be only slightly higher than in the baseline. This is because traditional cookstoves are mostly replaced by improved cookstoves (see Fig. 3), which are still relatively cheap compared to the modern cookstoves. The Biogas digester subsidy scenario does lead to much higher capital cost than in the baseline, because of the relatively high capital cost of biogas digesters. In the period 2016-2030, about a third of total capital cost consist of purchases of biogas digesters, even though the share of biogas in the energy mix is very small. The Enhanced fuel distribution scenario projects a small increase in capital cost compared to the baseline, mainly because the relatively expensive biogas digesters are replaced by LPG and natural gas. The target scenarios show considerably higher capital cost than the baseline in 2030, although in absolute terms the numbers remain low. In the No traditional cookstoves scenario, the capital cost is almost three times as high as in the baseline (1.6 billion annually) in the period 2016-2030. In the Modern fuel scenarios, the capital cost is four times as high as in the baseline in the same period. The capital expenditure under electric cooking scenario is similar to the modern fuel scenario as electric cookstoves replace both the expensive biogas digesters and the relatively cheaper options of LPG and natural gas cookstoves.

By 2030, no traditional biomass cookstoves scenario shows the lowest total cost, followed by the Electric cooking, Cookstove subsidy and Biogas digester subsidy scenarios. All these scenarios show lower annual cost for cooking than in the baseline. The Modern fuel scenario shows higher cost, especially due to relative high costs for gaseous fuels and electricity. The Enhanced fuel distribution scenario has the highest total cost of the three policy scenarios. This is due a very high share of gaseous fuels in this scenario, replacing cheaper options as a consequence of the fuel distribution enhancement. As a significant share of the cost will be paid for by public money in setting up the distribution network, the cost for the households are in fact the lowest of all policy scenarios. This implies that a large sum of public money is needed to enhance fuel distribution (about USD 3 billion by 2030). The capital expenditure in the period 2030-2050 in baseline and policy scenarios is four times the investment in the previous period driven by a rapid growing population and switches to LPG, natural gas and biogas cookstoves. More detail on projections after 2030 is presented in section 4 of the SI.

\subsection{Health impacts - child mortality}

In 2010 in Sub-Saharan Africa, HAP was estimated to be responsible for more than $40 \%$ of total ALRI deaths in children under 5 [3]. In the baseline scenario, attributable child mortality reduces from around 225 thousand in 2016 to 135 thousand in 2030 (see Fig. 5). The policy scenarios only show modest improvements in child mortality by 2030 , as the share of biomass use on traditional stoves remains high. Furthermore, the reduction in the relative risk when switching from a traditional cookstove to an improved cookstove is only small, even though the concentration levels decrease substantially. Only the Enhanced fuel distribution scenario shows significant improvements (around 20\% relative to 


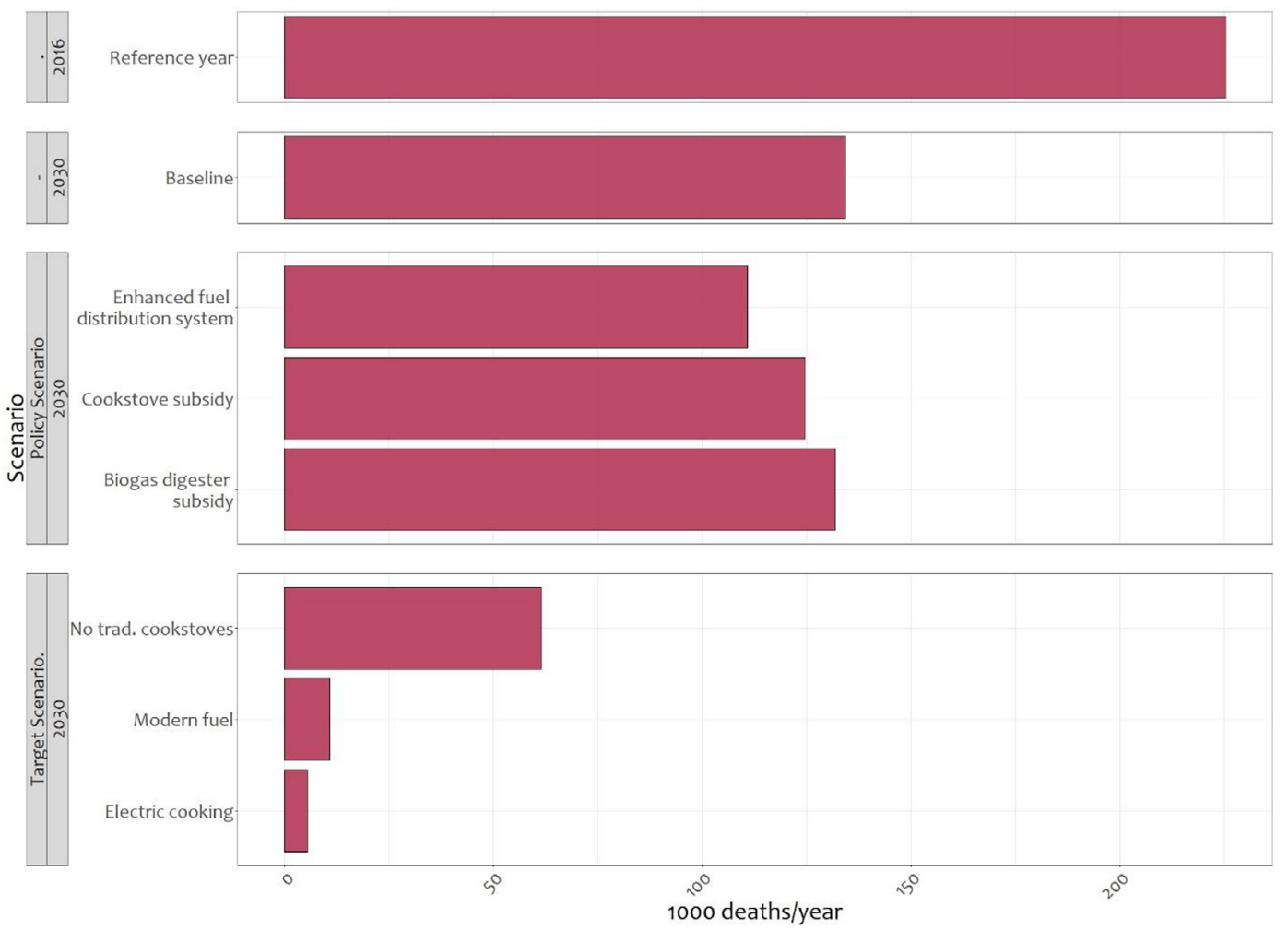

Fig. 5. ALRI child death attributable to household air pollution in SSA.
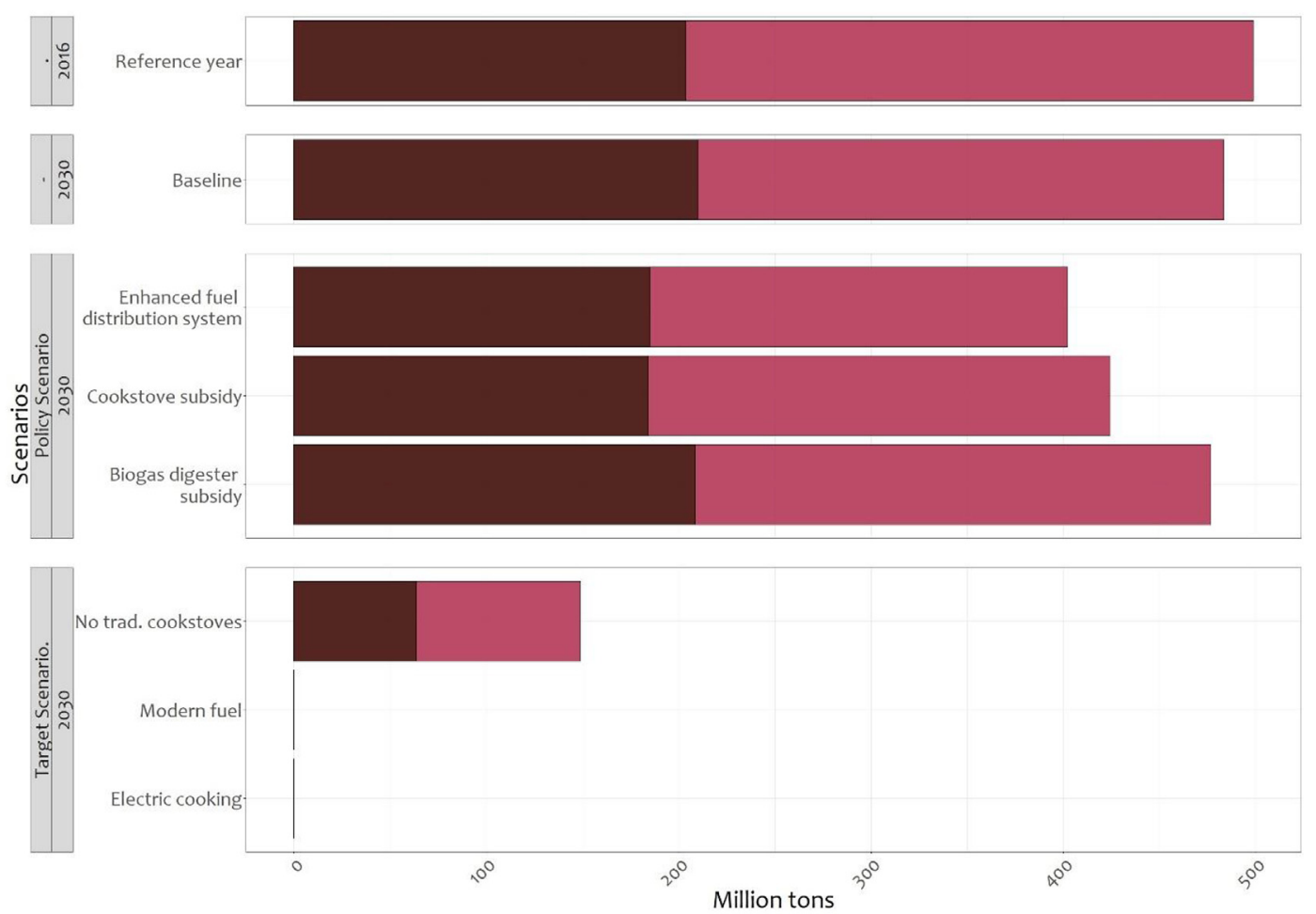

Fuelwood demand C Charcoal — Firewood

Fig. 6. Fuel-wood demand for charcoal and firewood in SSA. 
baseline), as biomass, mostly used in combination with a traditional stove, is partly replaced by LPG and natural gas with 90-99\% less $\mathrm{PM}_{2.5}$ emissions compared to open wood fires.

The three target scenarios show much higher impacts on child mortality. Currently, improved biomass stoves are in the range of Tier 0-2 emission standards and advanced biomass stoves in Tier 2-3. Only well-performing fan gasifiers and, to a lesser extent, natural-draft gasifier stoves approach the emission levels of LPG [35]. When phasing out the use of traditional biomass stoves, attributable mortality is reduced by around $50 \%$ by 2030 , compared to baseline levels. Also phasing-out biomass use in combination with improved and advanced cookstoves reduces attributable child mortality with 95-99\%, with a higher emphasis on HAP-free electric cooking further reducing attributable child mortality.

\subsection{Risk of deforestation}

In 2016, the fuelwood demand in SSA was 498 million tons (203 million tons for charcoal and 295 million tons for firewood). In the baseline, the total demand for wood remains relatively constant in the short term (485 million tons, see Fig. 6) and declines to 200 million tons by mid-century driven by a shift away from biomass and efficiency improvements due to i) shifts towards more efficient cookstoves and fuels, and ii) efficiency improvements of stoves themselves (see Fig. 2 in SI). The policy scenarios show a slight decrease in fuelwood demand by 2030, especially the Enhanced fuel distribution and Cookstove subsidy scenarios, which show a 12 and $17 \%$ decrease in fuelwood demand compared to baseline, respectively.

The target scenarios show a much higher impact on fuelwood demand. Phasing out traditional cookstoves implies that fuelwood demand (148 million tons) could be $70 \%$ less than the projected demand in the baseline by 2030 . This is despite the still strong dependence on biomass in the baseline by 2030, as the shift from traditional to the more efficient improved and advanced cookstoves already leads to a much lower demand for wood.

Natural biomass production is estimated at 1340 million tons in 2015 and 1100 million tons in 2030. This is much higher than the projected demand in all scenarios (Fig. 7) and thus does not necessarily has to lead to increased deforestation. These findings are in line with those of Santos, Dekker [45], who concluded that the cumulative global supply of net primary production remains higher than the global demand for biomass. We have taken a more conservative approach, by taking into consideration only the potential growth of stems and branches in natural vegetation, instead of all net primary production. We still found that for Sub-Saharan Africa as a whole, total potential supply is much larger than the projected demand for wood. However, this conclusion only holds under the assumption that biomass is sustainably harvested which implies that the harvesting method is more important for reducing deforestation than the absolute demand for fuelwood. Moreover, on a more local level wood demand may be higher than supply. This is shown by Fig. 7. The potential supply of biomass is concentrated in the Congo Basin, the south-western part of West Africa, south-west Ethiopia and parts of Madagascar, while demand for fuelwood demand is highly concentrated in high population density settlements in eastern and western Africa (Fig. 7). Burundi, Rwanda, and large parts of Uganda and Nigeria face high local deficits due to their low-standing biomass. Similarly, Kenya, Ethiopia, Malawi, Burkina Faso and Ghana also show some local deficit areas. In these parts, the No traditional cookstove scenario leads to much lower local deficits than the other scenarios where biomass is used.

\subsection{GHG emissions}

The displacement of traditional cookstoves with more efficient biomass or modern-fuel cookstoves can reduce cooking-related GHG emissions considerably. In 2016, total GHG emissions from cooking in SSA amounted to $600 \mathrm{Mt} \mathrm{CO}_{2} \mathrm{e}$ (Fig. 8), which is almost equal to total $\mathrm{CO}_{2}$ emissions of Canada. By far the largest share (75\%) came from the burning of solid biomass in traditional cookstoves. In the baseline, GHG emissions are projected to decline slightly towards $540 \mathrm{Mt} \mathrm{CO}_{2} \mathrm{e}$ in 2030 due to efficiency improvements in cleaner biomass and modern fuel cookstoves (despite a $35 \%$ increase in cooking energy demand). The policy scenarios Enhanced fuel distribution and Cookstove subsidy result in a 7\% and $14 \%$ emission reduction by 2030 relative to Baseline, respectively as inefficient traditional cookstoves are replaced by either more efficient gas stoves or by more efficient biomass stoves. The Biogas digester subsidy scenario does not lead to significant net changes in GHG emissions by 2030 , as the subsidy mainly affects cooking technologies in the long term. The emissions from biomass burning are based on the assumption that a third of the biomass is nonrenewable [39]. Some studies provide higher estimates to how much of the biomass is unsustainably harvested [46,47] which would imply an even higher effect of switching to modern fuels on greenhouse gas emissions. The target scenarios show a strong effect on emissions already in the short term, as the inefficient traditional cookstoves are completely phased out by 2030 . The reductions compared to baseline in the target scenarios range from $42 \%$ in the No traditional cookstove scenario to $64 \%$ in the Modern fuel and Electric cooking scenarios. As shown in a previous study by Dagnachew, Lucas [48], the emissions from household electricity use could decline further if electricity is produced from low-carbon energy sources.

\section{Discussion}

There are a number of caveats in our analysis. First of all, our results are based on historical relationships between various drivers and cooking fuel and technology choice. Several studies show that monetary value of fuel [49], household income [18] and infrastructure [50] indeed play an important role in the choice of cooking technology. However, these relationships might change over time.

Second, our model does not include all factors that influence technology choice. Factors like household-head gender [51], household-head age [52], cultural preferences [53], education [54] and technical aspects of the cookstoves $[19,55,56]$ also play roles in cooking fuel and technology choices. Our model does not explicitly address the role of these determinants.

Third, cooking fuel choice is not a binary process. Our analysis is based on the households' choice for a primary fuel for cooking. However, empirical studies [57] show that households do not wholly abandon one fuel in favour of another, but rather modern fuels are slowly integrated into energy-use patterns, resulting in a mix of traditional and modern cooking fuels; a phenomenon referred to as 'fuel-stacking'. Due to data limitations and the resulting complexity of the model, we do not capture this phenomenon in our model.

Fourth, availability of data is limited. The results of the analysis are driven by the underlying data, which is collected from several sources that often use various methodologies and inconsistent definition of variables. Besides, the purchase costs, fuel prices, and stove performance could differ locally and could have potential implications on fuel switching.

Finally, long-term projections are surrounded by many uncertainties, amongst others by socio-economic drivers like 
Demand under Baseline scenario

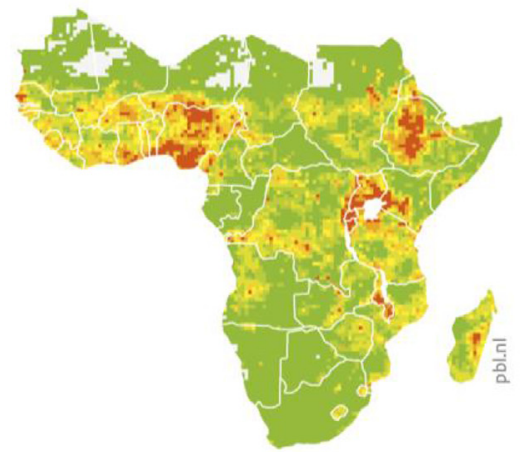

Supply under Baseline scenario

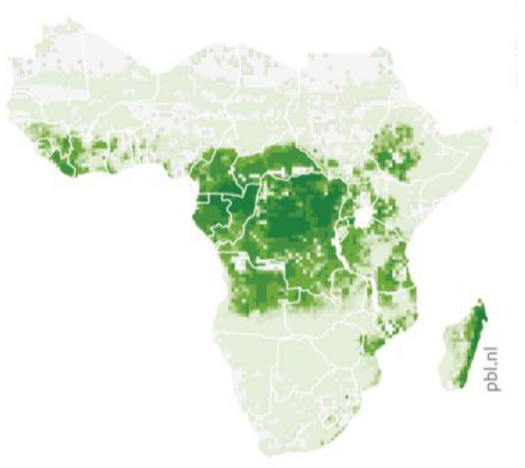

Demand under No traditional cookstove scenario

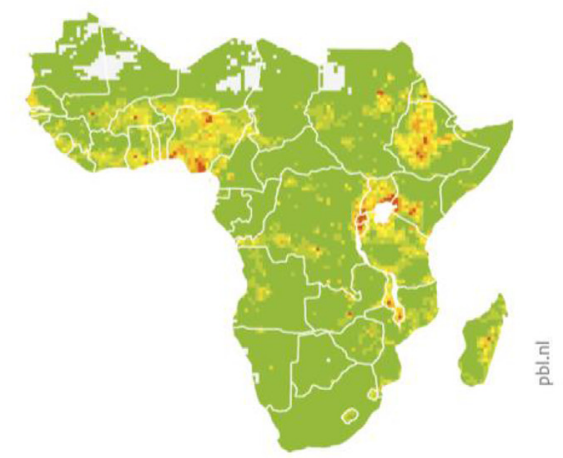

Demand (1000 tonnes per grid cell)

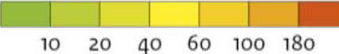

Supply (1000 tonnes per grid cell)

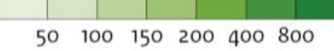

No demand or supply

Source: PBL

Fig. 7. Fuelwood demand and potential supply in 2030.

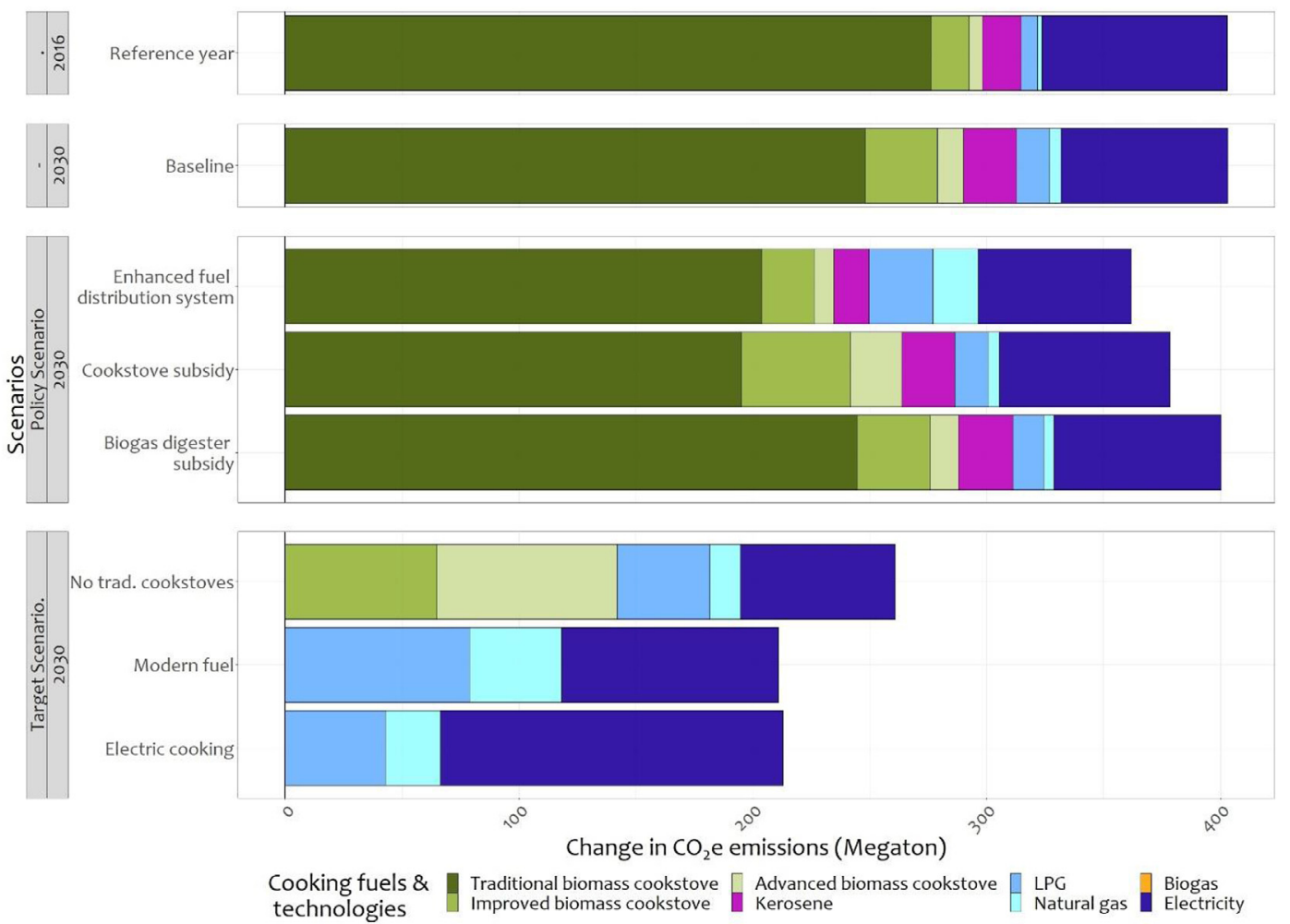

Fig. 8. GHG emissions from household cooking. 
population growth, urbanization and economic development. In this study, we focussed on a specific set of assumptions regarding population, income, lifestyle and fuel prices. Obviously, these factors are inherently uncertain. The SSP scenarios cover a wider set of assumptions than only SSP2. To explore the impact of these uncertainties we show the results for the cooking energy mix for SSP1, SSP2 and SSP3 in section 5 of the SI. The sensitivity analysis shows that in the short term, the results are not sensitive to socioeconomic assumptions and energy demand, but in the long term (2050), they are. However, the total biomass demand varies from 450 to 520 million tons and emissions from 380 to $430 \mathrm{MtCO}_{2} \mathrm{eq}$ depending on the chosen SSP. Additionally, the model projections and our analysis neither cover the implementation nor the financing of these scenarios.

The results of our study is in line with the results reported in the IEA energy access outlook 2017 [16]. The IEA projection shows that, by 2030,900 million people are without clean cooking access in SSA under the new policy scenario. Our projection shows very close estimate of 895 million by 2030 under the baseline scenario. The outlook also projects that the cost of providing universal clean cooking access in sub-Saharan Africa by 2030 amounts to USD 1.7 billion per year, which is in the range of our estimate (USD 1.6 to 2.4 billion per year).

This study also shows the benefits of clean and modern energy access on health and the environment. According to our projection, universal access to clean and modern cooking energy could save the lives of up to hundred thousand children in 2030. It also considerably reduces deforestation and forest degradation and contributes to the reduction of up to $340 \mathrm{Mt} \mathrm{CO}_{2}$ emissions by 2030 . However, the transition can be hampered by the cost of purchasing a modern stove. Addressing this issue requires emphasis on innovative business models and scaling-up of micro-finance with special focus on the low-income population. Even after purchasing the stove, the continued and proper use of the stove can be hindered by high fuel cost for modern technologies. Hence, the focus on accessibility and affordability of modern fuels is crucial to harness the full benefits of the transition. At the same time, the results of this study highlight that if health and environmental cost of traditional fuels and technologies are internalized, the cost competitiveness of modern cooking solutions could increase significantly. As such, the challenges of universal access to clean and modern energy relate to broader socio-economic factors.

\section{Conclusions}

In this paper, we present two sets of scenarios for promoting cooking solutions in SSA, either focussing on specific policy measures or imposing the universal access target. With the above caveats in mind, we can draw the following conclusions from our analysis:

Neither the baseline nor any of the policy scenarios analysed lead to achieving SDG7.1 on clean cooking in SSA. Unless radical improvements are made with respect to the affordability and efficiency of clean cooking technologies, as well as an exceptionally rapid installation of modern fuel infrastructure, traditional biomass (firewood and charcoal) will have a significant share $(67 \%$ in our scenario) in the cooking energy mix for decades to come. Neither the baseline nor any of the policy scenarios come close to achieving SDG7.1 in SSA. Improved and advanced biomass cookstoves could therefore play an important role as interim-solutions in the transition, especially in rural areas.

Phasing out traditional biomass use may lead to lower total cost of cooking. The average total household costs for the no traditional cookstove scenario and electric cooking scenario are lower than those projected under the baseline and the policy scenarios. Given that the annual fuel cost is several times higher than the average annual capital cost, saving on fuel (either by changing to more efficient biomass cookstoves or by using less useful energy for cooking) will lead to large reductions in cost (up to $17 \%$ lower according to our results). At the same time, initial capital cost, though relatively low, is often one of the biggest barriers for the poorest households without stable and reliable income in SSA [2,58]. This implies that policies facilitating access to modern fuels, access to finance, and stimulate innovative business cases could help in the transition to clean and modern cooking solutions.

The transition to clean and modern cooking fuels and technologies could save the lives of $\mathbf{1 0 0}$ thousand children in 2030. Children under 5 years of age in SSA are disproportionately affected by HAP. Reducing the use of solid biomass, mineral coal and kerosene has considerable benefits on health and well-being. Our analysis shows that, while eliminating the use of traditional cookstoves could reduce child mortality attributed to HAP from pneumonia by $50 \%$ in 2030 compared to baseline, completely halting the use of solid biomass for cooking could reduce it by $99 \%$. This requires investment in awareness raising and communication of the negative side-effects of traditional biomass use, scaling-up innovative finance models for poor households, as well as financial and technical support for businesses.

Eliminating traditional cookstoves or halting the consumption of solid biomass all together can help save 335-485 million tons of fuelwood annually by $\mathbf{2 0 3 0}$. The inefficiency in combustion of biomass in traditional biomass cookstoves is such that eliminating the use of traditional cookstoves could save up to 335 million tons of fuelwood. Halting the consumption of solid biomass entirely could save up to 485 million tons of fuelwood. Under baseline assumptions, the total biomass demand in SSA is well below total biomass production. However, by 2030 , several parts in western Africa and eastern Africa could experience pressure due to higher demand for fuelwood than the local production capacities. The transition towards clean and modern fuels could therefore provide environmental benefits tackling forest degradation, deforestation, soil erosion, and other natural resource impacts resulting from fuelwood collection.

Even when assuming that the biomass is largely harvested sustainably, resulting in very limited $\mathrm{CO}_{2}$ emissions, switching to modern fuels could lead to a decrease in greenhouse gas emissions. Eliminating traditional cookstoves could save $225 \mathrm{Mt}$ $\mathrm{CO}_{2} \mathrm{e}$ from avoided emissions by 2030 , while halting the use of biomass entirely or cooking behaviour change could save $340 \mathrm{Mt}$ of $\mathrm{CO}_{2} \mathrm{e}$ (equivalent to a third of the total $\mathrm{CO}_{2}$ emissions in Africa in 2016). This is due to the low efficiency of biomass stoves and the fact that biomass burning emits $\mathrm{CH}_{4}, \mathrm{~N}_{2} \mathrm{O}$, and $\mathrm{BC}$ that have higher climate impacts than $\mathrm{CO}_{2}$. The avoided emission could be higher with higher proportion of unsustainably harvested biomass.

Efforts to achieve universal access to clean cooking solutions could be integrated within broader poverty alleviation and economic development policies. A transition towards clean cooking solutions can contribute to achieving a range of SDGs. In this study, we have discussed significant synergies with improving child health (SDG3), reducing greenhouse gas emissions (SDG13) and reducing deforestation, land degradation and biodiversity loss (SDG15). Coordinating initiatives and policies aiming to provide clean cooking solutions with policies and programs for (rural) education, health, universal access to electricity, climate change mitigation, environmental programs and industrialisation could increase synergies between the programs, facilitate the transition and bring the SDGs closer to realisation. Actions and programs could also explicitly consider gender and social aspects to address existing gender gaps in energy access. 


\section{Acknowledgement}

The research presented in this paper was funded by the Dutch Ministry of Foreign Affairs, the Netherlands, through its Directorate-General of Trade and International Cooperation. The work also benefitted from the funding of the European Horizon 2020 research programme, European Union, as part of the CDLINKS project (Linking Climate and Development PoliciesLeveraging International Networks and Knowledge Sharing) under grant agreement No 642147.

\section{Appendix A. Supplementary data}

Supplementary data to this article can be found online at https://doi.org/10.1016/j.energy.2019.116641.

\section{References}

[1] IEA. World energy outlook 2018. Paris: IEA; 2018.

[2] Schlag N, Zuzarte F. Market barriers to clean cooking fuels in sub-Saharan Africa: a review of literature. Stockholm Environment Institute; 2008.

[3] Stanaway JD, et al. Global, regional, and national comparative risk assessment of 84 behavioural, environmental and occupational, and metabolic risks or clusters of risks for 195 countries and territories, 1990-2017: a systematic analysis for the Global Burden of Disease Study 2017. The Lancet 2018;392(10159):1923-94.

[4] Karekezi S, et al. Energy, poverty and development. In: Global energy assessment - toward a sustainable future. Cambridge, UK and New York, NY, USA: Cambridge University Press; 2012. p. 152-90.

[5] Bailis R, et al. The carbon footprint of traditional woodfuels. Nat Clim Chang 2015;5(3):266-72.

[6] OECD/IEA. Worl energy outlook 2006. Paris: International Energy Agency; 2006.

[7] Bond TC, et al. Bounding the role of black carbon in the climate system: a scientific assessment. J Geophys Res: Atmosphere 2013;118(11):5380-552.

[8] Pearson TRH, et al. Greenhouse gas emissions from tropical forest degradation: an underestimated source. Carbon Balance Manag 2017;12(1).

[9] Pachauri S, et al. Pathways to achieve universal household access to modern energy by 2030. Environ Res Lett 2013;8(2):024015.

[10] Cameron C, et al. Policy trade-offs between climate mitigation and clean cookstove access in South Asia. Nature Energy 2016;1:15010.

[11] Fuso Nerini F, Ray C, Boulkaid Y. The cost of cooking a meal. The case of Nyeri County, Kenya. Environ Res Lett 2017;12(6):065007.

[12] Pachauri S, Rao ND, Cameron C. Outlook for modern cooking energy access in Central America. PLoS One 2018;13(6):e0197974.

[13] Stehfest E, et al. Integrated assessment of global environmental change with IMAGE 3.0: model description and policy applications. The Hague: PBL Netherlands Environmental Assessment Agency; 2014.

[14] van Ruijven BJ. Energy and development: a modelling approach. In: Copernicus institute for sustainable development and innovation, department of science, technology and society. Utrecht: Utrecht University; 2008.

[15] Daioglou V, van Ruijven BJ, van Vuuren DP. Model projections for household energy use in developing countries. Energy 2012;37(1):601-15.

[16] IEA. Energy access outlook 2017: from poverty to prosperity. Paris: IEA; 2017.

17] Ifegbesan AP, Rampedi IT, Annegarn HJ. Nigerian households' cooking energy use, determinants of choice, and some implications for human health and environmental sustainability. Habitat Int 2016;55:17-24.

[18] Makonese T, Ifegbesan AP, Rampedi IT. Household cooking fuel use patterns and determinants across southern Africa: evidence from the demographic and health survey data. Energy Environ 2018;29(1):20.

[19] Masera OR, Díaz R, Berrueta V. From cookstoves to cooking systems: the integrated program on sustainable household energy use in MexicoIX. Energy for Sustainable Development; 2005. 1.

[20] Hooper LG, et al. Traditional cooking practices and preferences for stove features among women in rural Senegal: informing improved cookstove design and interventions. PLoS One 2018;13(11):e0206822.

[21] Quinn AK, et al. An analysis of efforts to scale up clean household energy for cooking around the world. Energy Sustain Develop 2018;46:1-10.

[22] Smeets B, et al. Sub-Saharan Africa continues to depend on inefficient cooking technologies. McKinsey Energy Insights; 2017 [cited 2017 September]; Available from: https://www.mckinseyenergyinsights.com/insights/subsaharan-africa-continues-to-depend-on-inefficient-cooking-technologies/.

[23] Casteleyn H. Clean cooking in sub-Saharan Africa: modeling the cooking fuel mix to 2050. In: Division of Energy and Climate Studies Department of Energy Technology, School of Industrial Engineering and Management. KTH Royal Institute of Technology; 2017.

[24] van Vuuren DP, et al. Timer 2: model description and application. In:
Bouwman AF, Kram T, Goldewijk KK, editors. Integrated modelling of globa environmental change: an overview of IMAGE 2.4. Bilthoven: Netherlands Environmental Assessment Agency (MNP); 2006. p. 39-60.

[25] Doelman JC, et al. Exploring SSP land-use dynamics using the IMAGE model: regional and gridded scenarios of land-use change and land-based climate change mitigation. Glob Environ Chang 2018;48:119-35.

[26] Lucas, P., et al., Future impacts of environmental factors on achieving the SDC target on child mortality - a synergistic assessment. Global Environmental Change, submitted for publication.

[27] Lucas PL, et al. Future impacts of environmental factors on achieving the SDC target on child mortality - a synergistic assessment. In: PBL Working paper 24. The Hague: PBL Netherlands Environmental Assessment Agency; 2018.

[28] de Boer HS, van Vuuren D. Representation of variable renewable energy sources in TIMER, an aggregated energy system simulation model. Energy Econ 2017;64:600-11.

[29] Lucas PL, et al. Future impacts of environmental factors on achieving the SDC target on child mortality - a synergistic assessment. Glob Environ Chang $2019 ; 57$.

[30] van Ruijven BJ, et al. Long-term model-based projections of energy use and CO2 emissions from the global steel and cement industries. Resour Conserv Recycl 2016;112:15-36.

[31] van Sluisveld MAE, et al. Exploring the implications of lifestyle change in $2{ }^{\circ} \mathrm{C}$ mitigation scenarios using the IMAGE integrated assessment model. Technol Forecast Soc Chang 2016;102:309-19.

[32] Zubi G, et al. Development and assessment of a solar home system to cover cooking and lighting needs in developing regions as a better alternative for existing practices. Sol Energy 2017;155:7-17.

[33] UN. Energy for a sustainable future. New York: United Nations; 2010.

[34] Kaygusuz K. Energy services and energy poverty for sustainable rural development. Renew Sustain Energy Rev 2011;15(2):936-47.

[35] World Bank. Clean and improved cooking in Sub-Saharan Africa : a landscape report. Washington, D.C: World Bank Group; 2014.

[36] Daioglou V. Residential energy use scenarios, in department of geosciences Utrecht: Utrecht University; 2010.

[37] Jeuland MA, Pattanayak SK. Benefits and costs of improved cookstoves: assessing the implications of variability in health, forest and climate impacts. PLoS One 2012:7(2):e30338.

[38] Jeuland M, Soo J-ST. Analyzing the costs and benefits of clean and improved cooking solutions. Sanford School of Public Policy and Duke Global Health Institute; 2016.

[39] FAO. Sustainable woodfuel for food security A smart choice: green, renewable and affordable Working paper. Rome: Food and Agriculture Organization of the United Nations; 2017.

[40] IPCC. 2006 IPCC guidelines for national greenhouse gas inventories. Available from: https://www.ipcc-nggip.iges.or.jp/public/2006gl/vol2.html; 2006.

[41] IPCC. Working group III contribution to the fifth assessment report of the intergovernmental panel on climate change. In: Mitigation of climate change. New York, NY, USA: Intergovernmental Panel on Climate Change; 2014.

[42] Kc S, Lutz W. The human core of the shared socioeconomic pathways: population scenarios by age, sex and level of education for all countries to 2100 Glob Environ Chang 2017;42:181-92.

[43] Dellink R, et al. Long-term economic growth projections in the shared socioeconomic pathways. Glob Environ Chang 2017;42:200-14.

[44] Jiang L, O'Neill BC. Global urbanization projections for the shared socioeconomic pathways. Glob Environ Chang 2017:42:193-9.

[45] Santos MJ, et al. Modeling the effects of future growing demand for charcoa in the tropics. Front Environ Sci 2017;5.

[46] Wilson DL, et al. Avoided emissions of a fuel-efficient biomass cookstove dwarf embodied emissions. Develop Eng 2016;1:8.

[47] Drigo R, et al. Pan-tropical analysis of woodfuel supply, demand and sustainability. Yale School of forestery and environmental studies; 2014.

[48] Dagnachew AG, et al. Trade-offs and synergies between universal electricity access and climate change mitigation in Sub-Saharan Africa. Energy Policy $2018 ; 114(C): 12$

[49] Morrissey J. Africa: a guide for advocates and policy makers: Part 2: addressing energy poverty. In: Pfeifer $\mathrm{K}$, editor. Oxfam's research backgrounders. Oxfam; 2017.

[50] Hou B-D, et al. Cooking fuel choice in rural China: results from microdata. J Clean Prod 2017;142:538-47.

[51] Karimu A, Mensah JT, Adu G. Who adopts LPG as the main cooking fuel and why? Empirical evidence on Ghana based on national survey. World Dev 2016;85:43-57.

[52] Kelebe HE, et al. Determinants for adoption decision of small scale biogas technology by rural households in Tigray, Ethiopia. Energy Econ 2017;66: $272-8$.

[53] Toonen HM. Adapting to an innovation: solar cooking in the urban households of Ouagadougou (Burkina Faso). Phys Chem Earth, Parts A/B/C 2009;34(1-2): $65-71$.

[54] Mekonnen A, Köhlin G. Determinants of household fuel choice in major cities in Ethiopia. In: Environment for development. Göteborg: School of Business, Economics and Law at University of Gothenburg; 2008.

[55] Shen G, et al. Factors influencing the adoption and sustainable use of clean fuels and cookstoves in China -a Chinese literature review. Renew Sustain 
Energy Rev 2015;51:741-50.

[56] Nlom J, Karimov A. Modeling fuel choice among households in northern Cameroon. Sustainability 2015;7(8):9989-99.

[57] van der Kroon B. Climbing the African energy ladder: internal and external factors influencing household demand for improved cookstoves and modern fuels in sub-Saharan Africa. Amsterdam: Vrije Universiteit; 2016.

[58] Malla S, Timilsina GR. Household cooking fuel choice and adoption of improved cookstoves in developing countries: a review. In: Policy research working paper. The World Bank; 2014. 